\title{
Práticas de Gestão do Conhecimento e Capacidade Absortiva Aplicadas à Melhoria de Desempenho e Qualidade na Manutenção Industrial
}

\author{
Knowledge Management Practices and Absorptive Capacity Applied to Performance and Quality \\ Improvement in Industrial Maintenance \\ Prácticas de Gestión del Conocimiento y Capacidad de Absorción Aplicada al Desempeño y Mejora \\ de la Calidad en el Mantenimiento Industrial
}

Recebido: 05/02/2021 | Revisado: 10/02/2021 | Aceito: 16/02/2021 | Publicado: 24/02/2021

\author{
Wladmir Zyrianoff \\ ORCID: https://orcid.org/0000-0002-6235-6489 \\ Universidade Metodista de São Paulo, Brasil \\ E-mail: wzyrian@gmail.com \\ Marcio Shoiti Kuniyoshi \\ ORCID: https://orcid.org/0000-0003-2973-9645 \\ Pontifícia Universidade Católica de São Paulo, Brasil \\ Universidade Metodista de São Paulo, Brasil \\ E-mail: mskunfea@gmail.com \\ Marcos Antonio Gaspar \\ ORCID: https://orcid.org/0000-0002-2422-2455 \\ Universidade Nove de Julho, Brasil \\ E-mail: marcos.antonio@uni9.pro.br \\ Hugo do Nascimento \\ ORCID: https://orcid.org/0000-0002-4655-8697 \\ Universidade Nove de Julho, Brasil \\ E-mail: hugonascimento2809@gmail.com
}

\begin{abstract}
Resumo
Esta pesquisa tem como objetivo identificar e descrever como as práticas de gestão do conhecimento e a capacidade absortiva têm sido utilizadas para a melhoria do desempenho e qualidade na área de manutenção de uma indústria automobilística do ABC paulista. Para tanto, executou-se pesquisa descritiva de cunho qualitativo mediante a utilização do método de estudo de caso. Foram aplicados como instrumentos de investigação roteiro de entrevista semiestruturada, observação direta não participativa e pesquisa documental em registros de arquivos e artefatos físicos da empresa analisada. Foram entrevistados gestores e funcionários técnicos de elevada hierarquia da área de manutenção industrial da empresa prospectada. Por meio da análise e triangulação dos dados auferidos na pesquisa de campo executada, identificou-se que os profissionais da área de manutenção percebem a necessidade da gestão do conhecimento em seus processos de trabalho e que as práticas de gestão do conhecimento têm influência na capacidade absortiva da área. Ficou ainda evidente que a capacidade absortiva influencia no desempenho e qualidade das ações desempenhadas pelos funcionários da manutenção. Como conclusão, os resultados da pesquisa permitem inferir que se as organizações derem maior atenção às práticas de gestão do conhecimento e à capacidade absortiva por elas proporcionada, poderão ser capazes de criar e sustentar vantagens competitivas sobre seus concorrentes. Palavras-chave: Gestão do conhecimento; Capacidade absortiva; Desempenho; Manutenção industrial.
\end{abstract}

\begin{abstract}
This research aims to identify and describe how knowledge management practices and absorptive capacity have been used to improve performance and quality in the maintenance area of an automobile industry in the State of São Paulo (Brazil). In order to achieve this goal, a qualitative descriptive research was carried out using the case study method. There were applied as investigation instruments semi-structured interview, direct non-participatory observation and documentary research in records of files and physical artifacts of the analyzed company. Managers and technical employees of high hierarchy of the industrial maintenance area of the prospected company were interviewed. It was identified that the professionals in the maintenance area perceive the need for knowledge management in their work processes and that knowledge management practices have an influence on the absorptive capacity of the area. It was also achieved that the absorptive capacity influences the performance and quality of the actions performed by the maintenance employees. In conclusion, the results of the research allow us to infer that if organizations pay greater attention to knowledge management practices and the absorptive capacity they provide, they can create and sustain competitive advantages over their competitors.
\end{abstract}


Keywords: Knowledge management; Absorptive capacity; Performance; Industrial maintenance.

\section{Resumen}

Esta investigación tiene como objetivo identificar y describir cómo las prácticas de gestión del conocimiento y la capacidad de absorción se han utilizado para mejorar el rendimiento y la calidad en el área de mantenimiento de una industria automotriz en Región del ABC de São Paulo (Brasil). Con este fin, se llevó a cabo una investigación cualitativa descriptiva utilizando el método de estudio de caso. El guión de la entrevista semiestructurada, la observación directa no participativa y la investigación documental en registros de archivos y artefactos físicos de la empresa analizada se aplicaron como instrumentos de investigación. Se entrevistó a gerentes y empleados técnicos de alta jerarquía del área de mantenimiento industrial de la empresa prospectiva. A través del análisis y triangulación de los datos obtenidos en la investigación de campo realizada, se identificó que los profesionales del área de mantenimiento perciben la necesidad de gestión del conocimiento en sus procesos de trabajo y que las prácticas de gestión del conocimiento influyen en la capacidad de absorción de la zona. También era evidente que la capacidad de absorción influye en el rendimiento y la calidad de las acciones realizadas por los empleados de mantenimiento. En conclusión, los resultados de la investigación nos permiten inferir que si las organizaciones prestan mayor atención a las prácticas de gestión del conocimiento y a la capacidad de absorción que proporcionan, pueden ser capaces de crear y mantener ventajas competitivas sobre sus competidores.

Palabras clave: Gestión del conocimiento; Capacidad de absorción; Rendimiento; Mantenimiento industrial.

\section{Introdução}

A velocidade das mudanças nas quais as organizações, governos e cidadãos estão inseridos acaba por impor a necessidade de melhor entendimento do atual contexto de negócios. De acordo com Vieira (2017), essa onda de mudanças é tratada como Indústria 4.0. Kang et al. (2016) explicitam que a indústria 4.0 é baseada num conjunto de várias tecnologias que impõe a necessidade de renovação estratégica por parte das empresas, qualificação dos profissionais, bem como adaptação por parte das instituições de ensino e governos. Inseridas neste ambiente dinâmico e complexo, as organizações têm o desafio de realizar a leitura dos sinais do ambiente externo que podem impactar seu desempenho e, consequentemente, as organizações buscam dar respostas a essas demandas ambientais e, assim, prover o mercado com produtos e serviços inovadores e de melhor qualidade (Kang et al., 2016).

Tubino (2017) e Lemos et al. (2011) corroboram a ideia que a melhoria do desempenho das organizações depende da sua velocidade de resposta às demandas ambientais, implicando assim na sua própria sobrevivência e competitividade. É neste contexto, portanto, que o conhecimento torna-se recurso importante e imprescindível para as organizações contemporâneas. Isto porque o conhecimento é considerado um recurso-chave para a competitividade da organização. Por meio da recombinação permanente de conhecimento corporativo é que as organizações conseguem inovar, desenvolver novas competências essenciais e dar respostas rapidamente às mudanças mercadológicas, mantendo-se assim competitivas em ambiente cada vez mais dinâmicos (Dávila, 2016).

Considerando o conhecimento como um recurso estratégico, as organizações buscam então gerenciar este importante recurso, bem como, desenvolver capacidades visando assim identificar, adquirir, assimilar e aplicar conhecimentos em seus produtos, processos e serviços. Nesse sentido, pesquisas sobre a capacidade absortiva da empresa e, especificamente, sobre capacidades dinâmicas surgem como um meio de compreender de forma aprofundada como as organizações buscam desenvolver e aplicar estas capacidades em seus respectivos negócios e processos, criando assim valor para clientes e stakeholders (Dávila, 2016; Kianto \& Andreeva, 2014; Mau \& Stewart, 2013; Andreeva \& Ikhilchik, 2011).

Face ao contexto apresentado, o objetivo desta pesquisa é identificar e descrever como as práticas de gestão do conhecimento e a capacidade absortiva têm sido utilizadas para a melhoria do desempenho e qualidade da área de manutenção de uma indústria automobilística do $\mathrm{ABC}$ paulista. 


\section{Referencial Teórico}

\subsection{Conhecimento, knowledge-based view (KBV) e gestão do conhecimento (GC)}

De acordo com Dávila (2016), o conhecimento está ligado à experiência e à reflexão humana, podendo ser encontrado no indivíduo ou no grupo, ou ainda embrenhado em rotinas ou processos de trabalho nas empresas. Os resultados da aplicação do conhecimento em processos de negócio exprimem a capacidade melhorada de tomada de decisão e melhores ações para se atingir algum propósito na empresa.

Ichijo e Nonaka (2007) ressaltam que o conhecimento nasce a partir da interação dinâmica entre objetividade e subjetividade do indivíduo ao idealizar novas práxis para interação junto ao seu meio, proporcionando assim a criação de conhecimento novo. Deste modo, fica evidente que o conhecimento é um ativo intangível estreitamente ligado à atividade humana, e no contexto atual, figura como base para a criação de valor na empresa.

Em função da importância do recurso conhecimento para as empresas, a teoria denominada visão baseada no conhecimento (KBV - Knowledge Management View) apregoa que o conhecimento tácito dos indivíduos seja a fonte primeira de criação e sustentação de vantagens competitivas pela empresa. O conhecimento tácito pode formar a base da vantagem competitiva porque é único e geralmente agrega valor por ser difícil de imitar, sendo ainda raro, valioso e/ou insubstituível. No entanto, é importante destacar que pelo fato do conhecimento ser inerente aos indivíduos, um desafio para a gestão deste relevante recurso é a capacidade de integrar o conhecimento tácito dos indivíduos e aplicá-lo a novos produtos e serviços (Eisenhardt \& Santos, 2000). Bernardo Junior et al. (2018) argumentam que a aplicação da visão baseada em recursos na empresa pode viabilizar a criação de diferenciais competitivos em prol desta.

Além disso, Kogut e Zander, (1996); Kogut, (2000) e Eisenhardt e Santos (2000) enfatizam que o conhecimento também pode ser integrado externamente por meio de redes relacionais que extrapolam as fronteiras organizacionais. Essas redes de profissionais e organizações fornecem mecanismos eficientes para acessar e integrar novos conhecimentos, especialmente em ambientes de alta volatilidade, nos quais a velocidade e o escopo da integração de conhecimentos são fundamentais para sustentar a vantagem competitiva da empresa.

O conhecimento, portanto é considerado um ativo relevante e que as empresas precisam saber identificar, adquirir, compartilhar e aplicar de forma eficiente, visando assim criar valor e vantagens competitivas sustentáveis. Portanto, o conhecimento deve ser adequado aos objetivos estratégicos da organização (Dávila, 2016; Kuniyoshi, 2008).

A gestão do conhecimento é uma abordagem que busca gerenciar os principais processos relativos a este ativo relevante e estratégico para a empresa. De acordo com Kuniyoshi (2008), a gestão do conhecimento (GC) é uma das recentes abordagens da administração contemporânea cujo foco engloba o conceito de conhecimento como recurso estratégico. Pesquisadores do campo de estudos sobre organizações, estratégia, tecnologia da informação, entre outros, têm destacado a importância em se gerenciar o conhecimento, buscando identificar e compreender as práticas e iniciativas da gestão do conhecimento adotadas pelas empresas e suas principais contribuições para a eficiência e inovação. Em estudo conduzido por Morais et al. (2020) observou-se que a aplicação de práticas e ferramentas de gestão do conhecimento proporcionou elevação da eficiência e eficácia da organização, com consequente melhoria de seu desempenho.

\subsection{Práticas de gestão do conhecimento}

Staidel e Romano (2020) argumentam que as práticas de gestão do conhecimento são um importante instrumento para a sedimentação de conhecimentos nas empresas, não obstante Bessi et al. (2017) alertem sobre a dificuldade de gerir os conhecimentos numa organização. Kianto e Andreeva (2014) definem as práticas de Gestão do Conhecimento como um conjunto de atividades organizacionais e gerenciais intencionalmente executadas, que suportam e melhoram os processos de 
conhecimento da empresa. O Quadro 1 apresenta as práticas de gestão do conhecimento indicadas por Kianto e Andreeva (2014).

Quadro 1 - Práticas de Gestão do Conhecimento.

\begin{tabular}{|c|c|c|c|c|}
\hline Categoria & Dimensão & Descrição & Práticas & Autores \\
\hline \multirow{5}{*}{$\begin{array}{l}\text { PRÁTICAS DE GESTÃO } \\
\text { DO CONHECIMENTO }\end{array}$} & $\begin{array}{l}\text { GE- Gestão Estratégica } \\
\text { do Conhecimento }\end{array}$ & $\begin{array}{l}\text { Mapear e entender o } \\
\text { conhecimento chave da } \\
\text { empresa, rotinas de } \\
\text { avaliação de } \\
\text { competências. }\end{array}$ & $\begin{array}{l}\text { GE1. A nossa organização tem um entendimento claro do nosso conhecimento-chave atual. } \\
\text { GE2. Nossa organização tem uma visão clara de quais conhecimentos e competências são as mais relevantes para os nossos objetivos. } \\
\text { GE3. Nossos conhecimentos e competências organizacionais são avaliados sistematicamente. } \\
\text { GE4. A nossa organização realiza benchmarking para comparar o nosso conhecimento estratégico como dos nossos concorrentes. } \\
\text { GE5. Nossa organização reconhece explicitamente o conhecimento como um elemento-chave no planejamento estratégico. } \\
\text { GE6. Nossa organização tem uma estratégia clara para desenvolver conhecimento e competências. }\end{array}$ & \multirow{5}{*}{$\begin{array}{c}\text { Kianto e } \\
\text { Andreeva } \\
\text { (2014) }\end{array}$} \\
\hline & $\begin{array}{l}\text { CO - Cultura } \\
\text { Organizacional }\end{array}$ & $\begin{array}{l}\text { Promover, mensurar e } \\
\text { valorizar a iniciativa de } \\
\text { auto aprendizado e uso } \\
\text { de lições aprendidas. }\end{array}$ & $\begin{array}{l}\text { CO1. Verificar constantemente a existência de pensamento aberto e confiança nas relações chefe-colaborador e entre colaboradores. } \\
\text { CO2. Incorporar a flexibilidade do desejo de inovar na avaliação do desempenho. } \\
\text { CO3. Promover, mensurar e valorizar as iniciativas para o autoaprendizado. } \\
\text { CO4. Formalizar e acompanhar o uso de lições aprendidas. } \\
\text { CO5. Implantar Revisão de Aprendizagem, com foco nas lições aprendidas que não são bem-sucedidas. } \\
\text { CO6. Implantar colaboração interfuncional, por meio de reuniões informais, comunidades de prática, avaliação de cliente interno. }\end{array}$ & \\
\hline & $\begin{array}{l}\text { GRH - Gestão de } \\
\text { Recurso Humano }\end{array}$ & $\begin{array}{l}\text { Recompensar com } \\
\text { incentivos monetários } \\
\text { ou não o } \\
\text { compartilhamento de } \\
\text { conhecimentos. }\end{array}$ & $\begin{array}{l}\text { CB1. Recompensar o compartilhamento de conhecimento com incentivos monetários. } \\
\text { CB2. Recompensar o compartilhamento de conhecimento com incentivos não monetários. } \\
\text { CB3. Recompensar a criação de conhecimento com incentivos monetários. } \\
\text { CB4. Recompensar a criação de conhecimento com incentivos não monetários. } \\
\text { CB5. Incluir o compartilhamento de conhecimento na avaliação de desempenho dos empregados. }\end{array}$ & \\
\hline & $\begin{array}{l}\text { EO- Estrutura } \\
\text { Organizacional }\end{array}$ & $\begin{array}{l}\text { Utilizar equipes } \\
\text { interfuncionais para } \\
\text { projetos e ações } \\
\text { estratégicas, interação } \\
\text { informal na empresa. }\end{array}$ & $\begin{array}{l}\text { EO1. Habilitar sistemas de networking interno e espaços físicos de colaboração que permitam interações informais na empresa. } \\
\text { EO2. Implantar coaching e revisão após ação, para atingir diálogos abertos entre colaboradores e gerentes. } \\
\text { EO3. Criar um mapa de especialistas e utilizar equipes interdisciplinares com habilidades e experiências de diversas áreas. } \\
\text { EO4. Utilizar equipes interfuncionais para projetos e ações estratégicas. } \\
\text { EO5. Implantar sobreposição intencional de responsabilidades funcionais. }\end{array}$ & \\
\hline & $\begin{array}{l}\text { TIC- Tecnologias da } \\
\text { Informação e } \\
\text { Comunicação }\end{array}$ & $\begin{array}{l}\text { Utilizar internet, intranet } \\
\text { e ferramentas de e- } \\
\text { learning para facilitar o } \\
\text { conhecimento. }\end{array}$ & $\begin{array}{l}\text { TI1. Utilizar internet, intranet e ferramentas de e-learning para facilitar o compartilhamento de ideias e conhecimentos entre colaboradores. } \\
\text { TI2. Implantar rotinas de monitoramento de uso e manter atualizados os sistemas para gerir conhecimento (Portais, BD de conhecimento). } \\
\text { TI3. Verificar/assegurar que os sistemas de apoio à decisão suportem o trabalho baseado em conhecimento. } \\
\text { TI4. Assegurar que a arquitetura das TIC seja capaz de compartilhar informação e conhecimento na cadeia de valor estendida da empresa } \\
\text { (inclui stakeholders). } \\
\text { TI5. Verificar que os sistemas de TI suportemo trabalho do dia a dia, implantar indicadores. }\end{array}$ & \\
\hline
\end{tabular}

Fonte: adaptado de Kianto e Andreeva (2014).

Kianto e Andreeva (2014) identificaram um conjunto de 27 práticas, agrupadas em cinco dimensões: gestão estratégica do conhecimento, cultura organizacional, gestão do recurso humano, estrutura organizacional e tecnologias da informação e comunicação. Segundo Dávila (2016), esse conjunto de práticas de gestão do conhecimento é representativo e congrega as principais práticas identificadas pela Academia em dimensões geralmente aceitas pelos autores de referência na área.

Em estudo promovido por Pereira e Macieira (2019) foi possível estabelecer relação positiva entre o uso de práticas de gestão do conhecimento em prol do desenvolvimento das capacidades dinâmicas da empresa. Em outro estudo, Balle (2019) sinaliza a influência da capacidade absortiva no compartilhamento do conhecimento na organização.

\subsection{Capacidades dinâmicas e capacidade absortiva}

Dávila e Silveira Martins (2017) discorrem que a capacidade dinâmica de uma empresa seja formada pelo conjunto de capacidades produtivas que a organização utiliza para realizar suas operações. Kurtz et al. (2013) entende que as Capacidades Dinâmicas (CD) surgiu de uma lacuna da Visão Baseada em Recursos (Resource Based View - RBV), que é uma abordagem estratégica que representa a capacidade que as organizações possuem capaz de agregar, levantar e reconfigurar suas competências externas e internas, a fim de se adequarem rapidamente às mudanças do atual ambiente de negócios, bem como a utilização desses recursos para obtenção de vantagem competitiva.

A Visão Baseada em Recursos (RBV) parte da compreensão de que os recursos simplesmente existem e, nas suas 
origens, esta teoria está interessada na escolha e seleção de recursos estratégicos, deixando de lado a ênfase em explicar e/ou investigar como esses recursos são desenvolvidos e incorporados nas organizações. A abordagem das Capacidades Dinâmicas trata dessa lacuna ao utilizar uma perspectiva de processo para tentar explicar como as organizações se mantêm competitivas diante de mercados turbulentos e de cenários de mudanças complexas. Kurtz et al. (2013) indicam que a capacidade dinâmica é a utilização sistemática das competências internas para responder às exigências do ambiente externo, revigorando-as de acordo com a competição e as mudanças tecnológicas impostas pelo atual ambiente de negócios.

A abordagem de capacidades dinâmicas argumenta que a vantagem competitiva depende de processos organizacionais e gerenciais específicos, denominados 'capacidades dinâmicas', que são definidos como capacidade da empresa de integrar, construir e reconfigurar competências internas e externas para lidar ambientes em mudança (Teece \& Pisano et al., 1997, Popadiuk \& Nunes, 2018). Dessa forma, os principais desafios para os pesquisadores de estratégia têm sido definir a construção de capacidades dinâmicas, testar sua contribuição para o desempenho e entender a evolução dessas capacidades ao longo do tempo (Eisenhardt \& Santos, 2000).

Rocha (2018) assevera que a capacidade absortiva seja uma das facetas mais relevantes das capacidades dinâmicas. Nesse sentido, um aspecto especificamente importante é a capacidade de absorver conhecimentos externos para aproveitar as capacidades dinâmicas da organização. A capacidade absortiva, conforme apontam Zahra e George (2002), consiste em um importante componente para a renovação dos recursos organizacionais. Para Picoli e Takahashi (2016, p. 4), "essa capacidade de absorção é definida como rotinas e processos organizacionais por meio dos quais uma organização adquire, assimila, transforma e aplica conhecimentos".

O conceito de capacidade de absorção foi originalmente baseado na obra de Cohen e Levinthal (1990, p. 128), que a definiram como "a habilidade em reconhecer o valor de novas informações externas, assimilá-las e aplicá-las para fins comerciais". Conforme indicam Ali et al. (2018) e Bjorvatn e Wald (2018), a capacidade de absorção da empresa pode ser verificada em diferentes etapas de projetos ou processos por ela desempenhados. Assim, a habilidade em valorar conhecimentos de ordem externa está atrelada à base de conhecimento que a empresa possui em seus processos, pois, segundo Zahra e George (2002, p. 186), "ao utilizar aquilo que já é de conhecimento da organização, esta pode esboçar os elementos que deve captar externamente para melhorar os processos por ela realizados". Estudo conduzido por Rosa et al. (2020) destaca a capacidade absortiva calcada em conhecimentos como uma capacidade dinâmica viabilizadora da inovação na empresa.

Ferreira e Ferreira (2017) argumentam que a capacidade de absorção de conhecimentos na empresa se processe a partir das relações e interações entre os colaboradores em função das rotinas dos processos. Moraes (2019) identificou processos de aquisição de capacidade absortiva que contribuem para a identificação de conhecimentos na organização. Na visão de Guedes et al. (2017), pode haver diferentes estágios do desenvolvimento da capacidade de absorção de conhecimentos na empresa. A incorporação do conhecimento externo nas atividades internas da empresa a partir do reconhecimento, sua validade e relevância também foi tratada por Zahra e George (2002, p. 186) que, ajustando-se no conceito inicial de capacidade de absorção, propuseram uma "conceituação embasada em dimensões colocadas em dois grupos complementares: capacidade de absorção potencial e capacidade de absorção realizada”, conforme modelo apresentado na Figura 1. 
Figura 1 - Modelo de capacidade absortiva.

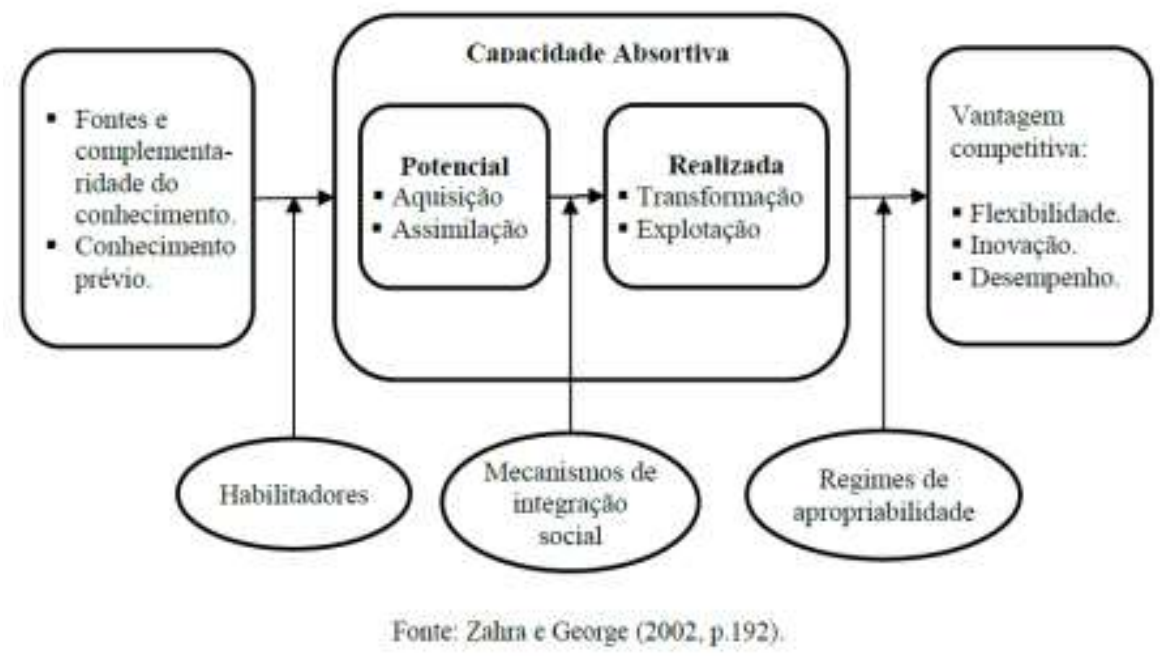

Fonte: Zahra e George (2002, p. 192).

Zahra e George (2002) identificaram em seu modelo, um conjunto de elementos antecedentes, tais como as fontes externas, a complementariedade do conhecimento e a base de conhecimento prévia. Por exemplo, quanto mais numerosas, diversas e complementares são as fontes de conhecimento externo disponíveis, maior a oportunidade de desenvolver uma Capacidade Absortiva Potencial. De forma similar, quanto maiores forem a experiência e a base de conhecimento prévio melhor será o direcionamento e a eficiência das capacidades de aquisição e assimilação do conhecimento obtido externamente. Os autores destacam também a existência de fatores habilitadores no modelo, os quais podem ser internos ou externos à organização. Os habilitadores criam ou evidenciam a necessidade de busca de conhecimento externo, podendo ser: crises internas, mudança de estratégia, invenções e outras rupturas tecnológicas no mercado, mudanças políticas, entre outros.

No modelo de Zahra e George (2002), as duas vertentes de Capacidade Absortiva Potencial (aquisição e assimilação) estão relacionadas à Capacidade Absortiva Realizada pelos mecanismos de integração social. Esses mecanismos são aqueles que facilitam o compartilhamento do conhecimento relevante entre os membros da organização, objetivando promover entendimento mútuo e compreensão, para posteriormente aplicar esse conhecimento.

Uma vez aplicado o conhecimento, Zahra e George (2002) salientam que a vantagem competitiva criada a partir da Capacidade Absortiva pode se evidenciar de três formas independentes, mas não excludentes: flexibilidade, inovação e desempenho. Assim, os autores salientam que a Capacidade Absortiva realizada influencia o desempenho organizacional por meio de inovações de processo. As inovações e melhorias nos processos fazem com que a empresa possa obter melhoria da qualidade na manutenção, por meio da capacidade de transformação, das inovações de produto, da capacidade de explotação e desenvolvimento de novos serviços na área de manutenção. De forma complementar, os autores propõem ainda que as organizações com melhor Capacidade Absortiva potencial são mais propensas a manter vantagens competitivas devido à maior flexibilidade para se reconfigurar constantemente de maneira mais eficiente em termos de custos e tempos (Dávila, 2016).

No Quadro 2 são apresentadas as dimensões da capacidade absortiva, seus componentes e as respectivas definições de cada dimensão, segundo Zahra e George (2002). 
Quadro 2 - Dimensões da capacidade absortiva.

\begin{tabular}{|c|c|c|c|}
\hline Categoria & Dimensão & Descrição & Autores \\
\hline \multirow{3}{*}{$\begin{array}{l}\text { CAPACIDADE } \\
\text { ABSORTIVA }\end{array}$} & $\begin{array}{l}\text { CAPAQ - Capacidade } \\
\text { Absortiva Potencial de } \\
\text { Aquisição }\end{array}$ & $\begin{array}{l}\text { Refere-se à capacidade da organização para identificar e adquirir conhecimento gerado externamente e crítico } \\
\text { para sua operação. }\end{array}$ & \multirow{3}{*}{$\begin{array}{c}\text { Zahra e } \\
\text { George } \\
(2002)\end{array}$} \\
\hline & $\begin{array}{l}\text { CAPAS - Capacidade } \\
\text { Absortiva Potencial de } \\
\text { Assimilação }\end{array}$ & $\begin{array}{l}\text { Permitem analisar, processar, interpretar e entender a informação de fontes externas. O fator que promove a } \\
\text { assimilação de conhecimento é a compreensão. }\end{array}$ & \\
\hline & $\begin{array}{l}\text { CART - Capacidade } \\
\text { Absortiva Realizada de } \\
\text { Transformação }\end{array}$ & $\begin{array}{l}\text { É a capacidade de desenvolver e refinar as rotinas e práticas que combinam o novo conhecimento coma base } \\
\text { de conhecimento prévio. }\end{array}$ & \\
\hline
\end{tabular}

Fonte: adaptado de Zahra e George (2002).

\subsection{Desempenho organizacional e avaliação da qualidade}

Kaplan e Norton (2001) definem o desempenho organizacional como um construto multidimensional, composto por elementos que são relevantes para a organização, tais como: rentabilidade, crescimento, sobrevivência e relacionamento com o cliente, dentre outros. Darroch (2005) desenvolveu um modelo de avaliação do desempenho com elementos a serem considerados segregados em duas dimensões: a) mensuração comparativa de desempenho: avalia as características rentabilidade, quota de mercado e crescimento e b) mensuração interna de desempenho: avalia a visão subjetiva do executivo sobre o próprio desempenho da organização e o nível de cumprimento dos objetivos organizacionais.

Segundo Dávila (2016), o modelo de Darroch (2005) é relevante exatamente pela simplicidade de seus componentes e por sua forte eficiência para representar o desempenho real da organização. Assim, a simplicidade é uma característica importante para reduzir erros na sua aplicação, considerando que a maior parte dos instrumentos de pesquisa baseada nos modelos de desempenho possui abordagem subjetiva para a coleta de dados.

Em relação à avaliação da qualidade, Kardec e Nascif (2001), Xenos (2004) e Lemos et al. (2011) apresentam conceitos ligados à Gestão da Qualidade Total e normas ISO Série 9000 e sua relação com a os processos de manutenção. Esses autores apresentam um programa de monitoramento da qualidade na manutenção, mas nenhum deles explica, em definitivo, o que é qualidade na manutenção. Não obstante, a falta de qualidade da manutenção é um dos fatores geradores de demanda de serviços de manutenção, conforme indicado na Figura 2. Tais fatores diminuem a disponibilidade, aumentam os custos e atenuam a satisfação dos clientes internos e externos. Logo, a satisfação do cliente da função manutenção nas organizações esta ligada aos produtos gerados pela área de manutenção, principalmente em empresas industriais (Lemos et al., 2011). 
Figura 2 - Demanda de Serviços de Manutenção.

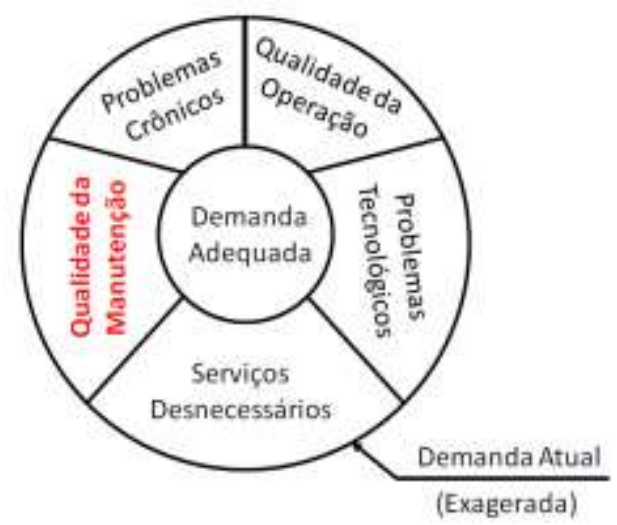

Fonte: adaptado Lemos et al. (2011).

A manutenção é essencialmente a prestação de um serviço para um cliente interno da organização. Para Kotler e Keller (2018), um serviço é qualquer ato ou desempenho, essencialmente intangível, que uma parte pode oferecer a outra, e que não resulta na propriedade de nada. Na norma NBR ISO 9000/2000 (Abnt, 2000) a manutenção está voltada aos resultados de pelo menos uma atividade desempenhada, necessariamente, pela interface entre o fornecedor e o cliente, sendo geralmente, intangível.

A falta de uma definição para a qualidade na manutenção deve-se ao fato de a função manutenção fornecer um serviço aos seus clientes internos e externos, bem como na dificuldade própria de definir o que é um serviço. Isto porque avaliar um serviço é mais complexo que avaliar um produto, por este ser tangível e o serviço não. Em função disso, Pieretti et al. (2020) reforçam a importância da atribuição de indicadores da qualidade de serviços praticados na manutenção de empresas industriais, visando assim o acompanhamento do desempenho alcançado na execução destes.

Portanto, serviços são essencialmente intangíveis e heterogêneos, sendo julgados pelo desempenho e pela experiência de quem os utiliza, com possibilidade de interpretação e julgamentos diferentes, conforme o prestador e expectativas dos usuários em questão (Pena et al. (2013).

A qualidade percebida em serviços pode ser considerada como a diferença entre o nível de eficácia do serviço e a expectativa do usuário. Parasuraman, Zheitaml e Berry (1985), no intuito de entender como os usuários percebiam e avaliavam a qualidade dos serviços, desenvolveram um estudo envolvendo doze grupos focais, sendo três em cada um dos quatro diferentes serviços investigados: banco de varejo, cartão de crédito, corretagem de ações, reparos e manutenção. Baseados nas percepções comuns entre os grupos, os autores definiram formalmente a qualidade em serviço como o grau e o tipo de discrepância entre as percepções e as expectativas dos usuários.

Deste de estudo de Parasuraman, Zheitaml e Berry (1985) definiu-se cinco dimensões de resultados para determinar as interrelações entre essas dimensões, sendo elas: tangibilidade, confiabilidade, responsividade, garantia e empatia. Tais “dimensões não são mutuamente exclusivas mas, ainda assim, fornecem uma importante estrutura para a compreensão das expectativas dos usuários, sendo aspectos que delineiam o serviço sob o ponto de vista de quem irá julgá-lo" (Pena et al., 2013, p. 1236).

Dessa forma, o Quadro 3 apresenta as duas dimensões propostas por Darroch (2005) sobre desempenho e as cinco dimensões propostas por Parasuraman, Zheitaml e Berry (1985) referentes à qualidade, descrevendo-se a categoria e cada dimensão indicada. 
Quadro 3 - Desempenho e qualidade.

\begin{tabular}{|c|c|c|c|}
\hline Categoria & Dimensão & Descrição & Autores \\
\hline \multirow{7}{*}{$\begin{array}{l}\text { DESEMPENHO e } \\
\text { QUALIDADE }\end{array}$} & $\begin{array}{l}\text { MCD - Mensuração } \\
\text { Comparativa de } \\
\text { Desempenho }\end{array}$ & Avalia as características Quota de mercado e Crescimento. & \multirow{2}{*}{$\begin{array}{l}\text { Darroch } \\
(2005)\end{array}$} \\
\hline & $\begin{array}{l}\text { MID - Mensuração } \\
\text { Interna de Desempenho }\end{array}$ & $\begin{array}{l}\text { Avalia a visão subjetiva do executivo sobre o próprio desempenho da organização, e o nível de cumprimento dos } \\
\text { objetivos organizacionais. }\end{array}$ & \\
\hline & $\begin{array}{l}\text { TQ - Tangibilidade na } \\
\text { Qualidade }\end{array}$ & $\begin{array}{l}\text { Diz respeito às instalações físicas, equipamento, pessoal e material que podem ser percebidos pelos cinco sentidos } \\
\text { humanos. }\end{array}$ & \multirow{5}{*}{$\begin{array}{c}\text { Parasuram } \\
\text { an, } \\
\text { Zheitaml e } \\
\text { Berry } \\
\text { (1985) }\end{array}$} \\
\hline & $\begin{array}{l}\text { CQ - Confiabilidade na } \\
\text { Qualidade }\end{array}$ & $\begin{array}{l}\text { Retrata um desempenho consistente, isento de não conformidade; deve cumprir com o que foi prometido, sem a } \\
\text { possibilidade de retrabalhos. }\end{array}$ & \\
\hline & $\begin{array}{c}\mathrm{RQ} \text { - Responsividade na } \\
\text { Qualidade }\end{array}$ & Atender voluntariamente aos usuários, prestando um serviço de forma atenciosa, com precisão e rapidez de resposta. & \\
\hline & $\begin{array}{l}\text { GQ - Garantia na } \\
\text { Qualidade }\end{array}$ & É identificada como a cortesia, o conhecimento dos trabalhadores e sua habilidade de transmitir confiança. & \\
\hline & $\begin{array}{l}\text { EQ - Empatia na } \\
\text { Qualidade }\end{array}$ & $\begin{array}{l}\text { Relata se a organização importa-se com o usuário e o assiste de forma individualizada, capacidade de demonstrar } \\
\text { interesse e atenção personalizada. }\end{array}$ & \\
\hline
\end{tabular}

Fonte: adaptado de Darroch (2005) e Parasuraman, Zheitaml e Berry (1985).

\section{Metodologia}

Para a realização desta pesquisa adotou-se um enfoque descritivo de natureza qualitativa, executada por meio de estudo de caso com perspectiva temporal aplicado em uma indústria automobilística da região do ABC paulista, focando-se a área de manutenção industrial. Para Godoy (1995, p.58), a abordagem da pesquisa descritiva "envolve a obtenção de dados descritivos sobre pessoas, lugares e processos interativos pelo contato direto do pesquisador com a situação estudada, procurando compreender os fenômenos segundo a perspectiva dos sujeitos". Segundo Pereira et al. (2018, p.67), a pesquisa qualitativa volta seu enfoque para "a interpretação por parte do pesquisador com suas opiniões sobre o fenômeno em estudo". Para Yin (2010, p.39) o estudo de caso é uma investigação empírica que "investiga um fenômeno contemporâneo em profundidade e em seu contexto de vida real, especialmente quando os limites entre o fenômeno e o contexto não são claramente evidentes".

A pesquisa de campo se deu com a realização de entrevistas semiestruturadas individuais e presenciais, ocorridas em outubro e novembro de 2018, além de observações não participativas feitas em novembro e dezembro de 2018. Foram entrevistados sete gestores da empresa pesquisada, sendo quatro gerentes e três engenheiros a área de manutenção industrial da organização analisada. Além disso, recorreu-se também à pesquisa documental com a avaliação de documentos, registros e artefatos relacionados às metas e objetivos organizacionais afixadas em murais, informações dispostas no site da empresa e na internet, bem como relatórios e atas de reuniões ocorridas na área de manutenção industrial. Assim sendo, a perspectiva temporal proporcionou análises ao longo da execução da pesquisa de campo executada, buscando informações que proporcionassem compreensão aos fenômenos estudados a partir da perspectiva dos participantes e atendendo aos objetivos de pesquisa estipulados.

Para a seleção dos participantes optou-se pelos critérios de acessibilidade e conveniência dos pesquisadores, devido à facilidade de contato com os diversos gestores da empresa enfocada. Os critérios para a seleção dos participantes da área de 
manutenção foram os seguintes: a) ser gerente ou possuir cargo de liderança na área de manutenção; b) possuir competência técnica com formação superior completa; c) ter experiência de no mínimo três anos como gestor em empresa na área de manutenção e; d) estar na função atual no negócio/unidade por pelo menos um ano completo.

O roteiro de entrevista semiestruturada aplicado foi estruturado em duas seções: a) dados do respondente, área e empresa e b) categorias e dimensões de análise extraídas da literatura acadêmica analisada (práticas de gestão do conhecimento, capacidade absortiva e desempenho/qualidade). O roteiro de entrevista formulado foi submetido previamente à análise de três especialistas na temática em questão, que realizaram a adaptação e validação definitiva do instrumento de pesquisa. Para respeitar o sigilo e a confidencialidade tanto da organização analisada, quanto de seus gestores, a empresa caso desta pesquisa será identificada doravante como 'Empresa Inova', enquanto que os participantes foram designados como 'Gerente Sênior', 'Gerente A', 'Gerente B', 'Gerente C', 'Engenheiro A', ‘Engenheiro B' e 'Engenheiro C'.

Em relação ao roteiro de observação não participante aplicado, adotou-se a seguinte estrutura: dados de identificação do fenômeno a ser observado, planejamento da observação, aspectos a serem observados (práticas de gestão do conhecimento, capacidade absortiva e desempenho/qualidade). Face aos objetivos de pesquisa delineados, bem como o referencial teórico delineado, as seguintes proposições foram elaboradas:

Proposição 1: Existe relação entre as práticas de gestão do conhecimento e a capacidade absortiva de conhecimento Buscou-se compreender como as organizações com um uso intensivo de práticas de Gestão do Conhecimento têm uma Capacidade Absortiva Potencial mais alta e se as organizações com um uso intensivo de práticas de Gestão do Conhecimento têm uma Capacidade Absortiva Realizada mais alta

Proposição 2: Existe relação entre capacidade absortiva de conhecimento e o desempenho organizacional e qualidade na manutenção - Buscou-se compreender se organizações com maior Capacidade Absortiva Potencial possuem melhor desempenho organizacional e qualidade e/ou se organizações com maior Capacidade Absortiva Realizada possuem melhor desempenho organizacional e qualidade na manutenção e, devido a isso, vantagem competitiva.

\section{Resultados e Discussão}

Primeiramente será exposta uma breve caracterização da organização enfocada nesta pesquisa. A Empresa Inova concentra a fabricação de mais de 30 modelos incluindo caminhões, chassis e plataformas para ônibus. Além disso, produzem eixos, motores, peças e componentes para aplicações industriais. A empresa adota um padrão mundial para o sistema de produção de veículos comerciais, baseado em cinco premissas: infraestrutura humana; padronização; qualidade, produtos e processos robustos; just-in-time e melhoria contínua. Esse sistema de produção é periodicamente avaliado, por meio de auditoria, em todas as fábricas de veículos comerciais da "Empresa Inova". Outro ponto a comentar é que a Indústria 4.0 já uma realidade na fábrica da "Empresa Inova". Inaugurada em 2018, a linha de fabricação de caminhões da empresa consegue mostrar na prática como as tecnologias digitais, a hiperconectividade, os dados na nuvem e a Internet das Coisas já fazem parte do cotidiano da empresa. Essas tecnologias vêm para melhorar a segurança dos operadores e a qualidade dos produtos, entretanto é imprescindível que o nível de qualificação e de conhecimento exigido de todos seja maior.

A apresentação está organizada em três blocos: o primeiro bloco trata da identificação das práticas da gestão do conhecimento na área de manutenção e da análise de sua influência na capacidade absortiva; o segundo bloco trata da verificação da influência da capacidade absortiva no desempenho e qualidade da área de manutenção na organização; já o terceiro bloco trata da confirmação se o desempenho e qualidade são influenciados pela gestão do conhecimento. 


\subsection{Práticas da gestão do conhecimento influenciando a capacidade absortiva}

De acordo com os entrevistados verificou-se que as práticas de gestão do conhecimento são disseminadas na organização. Segundo os respondentes da pesquisa, a estratégia da empresa considera que o conhecimento é relevante para a longevidade da organização. A empresa possui uma matriz de capacitação e, por meio desta ferramenta, é possível mapear os conhecimentos críticos necessários à organização. Entretanto, há possibilidade de melhoria, pois conforme colocado pelo Gerente Sênior e Engenheiro C, no passado essa estratégia era mais bem aplicada do que atualmente.

A razão desta observação se baseou na crise que perdura já há alguns anos no setor e, em decorrência disso, muitos treinamentos externos, por conseguinte mais caros, foram sensivelmente reduzidos. Todos os respondentes entendem que o turnover em função de aposentadoria ou outros motivos apresenta graves problemas para a área de manutenção. Vários funcionários experientes se aposentaram ou foram desligados de forma imediata e a transmissão dos conhecimentos críticos não foi suficiente para o bom desempenho da área, conforme relatado por um supervisor. Consequentemente, perdeu-se a oportunidade de agregar o conhecimento desses colaboradores que possuíam conhecimentos e expertises específicos para outros colaboradores da equipe, fazendo com que a área perdesse parte significativa do conhecimento adquirido ao longo do tempo. No Quadro 4 são apresentados os resultados da pesquisa, segregados a partir da classificação proposta por Kianto e Andreeva (2014). 
Quadro 4 - Resultados/Evidências encontradas nas Práticas de Gestão do Conhecimento a partir da classificação proposta por Kianto e Andreeva (2014).

\begin{tabular}{|c|c|c|c|c|}
\hline Categoria & Dimensão & Descrição & Autores & Resultados/Evidências \\
\hline \multirow{5}{*}{$\begin{array}{c}\text { PRÁTICAS DE } \\
\text { GESTÃO DO } \\
\text { CONHECIMENTO }\end{array}$} & $\begin{array}{l}\text { GE - Gestão } \\
\text { Estratégica do } \\
\text { Conhecimento }\end{array}$ & $\begin{array}{l}\text { Mapear e entender } \\
\text { o conhecimento } \\
\text { chave da empresa, } \\
\text { rotinas de avaliação } \\
\text { de competências. }\end{array}$ & \multirow{5}{*}{$\begin{array}{c}\text { Kianto e } \\
\text { Andreeva } \\
(2014)\end{array}$} & $\begin{array}{l}\text { A Gestão Estratégica de Conhecimento é primordial; } \\
\text { Tem implantado o TOS (Trucks Operating System); } \\
\text { Matriz de Capacitação dentro do TOS que avalia competências e desenvolve conhecimentos; } \\
\text { Projeto leadership } 2020 \text { que desenvolve o benchmark entre empresas do grupo; } \\
\text { Benchmarking de conhecimento com empresas no desenvolvimento de novos projetos / } \\
\text { processos ou materiais; } \\
\text { O processo de aposentadoria, ou "turnover" é contemplado e é focada na Matriz de } \\
\text { Capacitação, entretanto não está sendo desenvolvido de forma adequada. }\end{array}$ \\
\hline & $\begin{array}{l}\mathrm{CO} \text { - Cultura } \\
\text { Organizacional }\end{array}$ & $\begin{array}{l}\text { Promover, } \\
\text { mensurar e valorizar } \\
\text { a iniciativa de auto } \\
\text { aprendizado e uso } \\
\text { de lições } \\
\text { aprendidas. }\end{array}$ & & $\begin{array}{l}\text { A relação chefe-colaborador e entre colaboradores é muito boa e contínua; } \\
\text { "Empowerment" há promoção, mensuração e valorização às iniciativas para o } \\
\text { autoaprendizado; } \\
\text { As reuniões informais não promovem a colaboração interfuncional, entretanto existem reuniões } \\
\text { formais periódicas que suprem essa colaboração interfuncional; } \\
\text { Shop Floor Management, trabalho em grupo e nas reuniões do Momento Lean; } \\
\text { As lições aprendidas são disseminadas e sistematizadas como boas práticas, entretanto não foi } \\
\text { evidenciado. }\end{array}$ \\
\hline & $\begin{array}{l}\text { GRH - Gestão } \\
\text { de Recurso } \\
\text { Humano }\end{array}$ & $\begin{array}{l}\text { Recompensar com } \\
\text { incentivos } \\
\text { monetários ou não } \\
\text { o compartilhamento } \\
\text { de conhecimentos. }\end{array}$ & & $\begin{array}{l}\text { A “Empresa Inova” tem o "Prêmio Estrela e o Momento Lean”, podendo receber prêmios } \\
\text { não monetários além da satisfação pessoal; } \\
\text { Na avaliação de desempenho dos funcionários (LEAD) é incluído o compartilhamento de } \\
\text { conhecimentos, inclusive com metas de desempenho individual. }\end{array}$ \\
\hline & $\begin{array}{l}\text { EO - Estrutura } \\
\text { Organizacional }\end{array}$ & $\begin{array}{l}\text { Utilizar equipes } \\
\text { interfuncionais para } \\
\text { projetos e ações } \\
\text { estratégicas, } \\
\text { interação informal } \\
\text { na empresa. }\end{array}$ & & $\begin{array}{l}\text { A “Empresa Inova” possui sistemas de networking interno e espaços físicos de colaboração } \\
\text { que permitem interações na empresa; } \\
\text { Shop Floor Management, que é uma reunião diária que procura atender os problemas da área; } \\
\text { TOS Expert, projeto interdisciplinar sistematizado que tem por objetivo resolver os grandes } \\
\text { problemas; } \\
\text { O mapa de especialistas é obtido da Matriz de Capacitação; } \\
\text { Quanto ao coaching, pode ser visto no Shop Floor Management, nas reuniões com o Gerente } \\
\text { Sênior (CGP-ciclo de gestão participativa) e com o diretor da área e de forma mais informal } \\
\text { com os gerentes realizando "coaching diário, sempre que o gerente julgar necessário". }\end{array}$ \\
\hline & $\begin{array}{l}\text { TIC - } \\
\text { Tecnologias da } \\
\text { Informação e } \\
\text { Comunicação }\end{array}$ & $\begin{array}{l}\text { Utilizar internet, } \\
\text { intranet e } \\
\text { ferramentas de e- } \\
\text { learning para } \\
\text { facilitar o } \\
\text { conhecimento. }\end{array}$ & & $\begin{array}{l}\text { São disponibilizadas internet, intranet e ferramentas de e-learning, denominado E-Training } \\
\text { facilitando o compartilhamento de ideias, a comunicação e o conhecimento; } \\
\text { Os sistemas são atualizados e mantidos pela área de TI; } \\
\text { Sistema SAP (Sistemas, Aplicativos e Produtos para Processamento de Dados), pelo qual o } \\
\text { colaborador, via smartfone ou computador, pode acessar a Ordem de Serviço, incluir fotos e } \\
\text { dados, encerrar a ordem, há a inserção de informações pertinentes à manutenção do } \\
\text { equipamento, disponibilizando essas informações para todos que forem executar o serviço. }\end{array}$ \\
\hline
\end{tabular}

Fonte: Autores.

O programa Leadership 2020 (benchmarking corporativo) busca, dentre outros objetivos, proporcionar nivelamento do serviço, capacitação pessoal e disseminação de boas práticas aos profissionais da empresa. Tal iniciativa faz com que a empresa invista em treinamento e capacitação de pessoal. Porém, há também o benchmark externo a ser considerado, que é feito junto aos concorrentes relativamente às novas tecnologias em processos, máquinas ou equipamentos. Pode-se afirmar que a área de manutenção da Empresa Inova operacionaliza as cinco dimensões de práticas de gestão do conhecimento indicadas por Kianto e Andreeva (2014), seja de modo formal ou informal, de forma sistêmica e com uma intensidade de uso da Tecnologia da Informação bastante intensa como suporte aos processos de Gestão do Conhecimento. Assim, esses processos criam, assimilam, compartilham, transformam e aplicam conhecimentos criando valor por meio de resultados expressos em desempenho e qualidade elevada na área de manutenção. Esta iniciativa é congregada num conjunto de atividades 
organizacionais e gerenciais observáveis, verificáveis e intencionalmente executadas para gerir o conhecimento da empresa e, dessa forma, influenciar na Capacidade Absortiva de seus profissionais e equipes.

Esta iniciativa da Empresa Inova identificada na pesquisa de campo vai ao encontro da teoria formulada por Kianto e Andreeva (2014), segundo a qual as organizações têm intensa preocupação por explorar o conhecimento externo para manterem sua competitividade. Segundo os autores, a competitividade sustentável depende não só de uma adequada execução dos processos de Gestão do Conhecimento da organização, mas também de como as empresas expandem e reconfiguram sua base de conhecimento, adicionando novos conhecimentos constantemente. Desta forma, com base nos estudos de Zahra e George (2002), é possível afirmar que as interações por meio de aprendizado com a prática estão conectadas com a memória organizacional, que influencia a capacidade de uma organização de gerenciar conhecimento.

\subsection{Influência da capacidade absortiva no desempenho e qualidade}

Na dimensão Capacidade Absortiva Potencial de Aquisição, Zahra e George (2002) descrevem que quanto maiores forem a experiência e base de conhecimento prévio, melhor será o direcionamento e a eficiência das capacidades de aquisição do conhecimento obtido externamente. Nesse sentido, todos os profissionais entrevistados demonstraram que a Capacidade Absortiva Potencial de Aquisição é presente na Empresa Inova, uma vez que esta se caracteriza pela ênfase no apoio interdepartamental para resolver problemas. Conforme relatado pelo Gerente B, as fases de planejamento, aquisição, instalação e operação refletem exatamente este apoio interdepartamental para resolução de problemas na organização, disseminando conhecimentos, conceitos e ideias relevantes pelos profissionais de diferentes equipes de trabalho, bem como pela busca e interesse por informações pertinentes à área, agregando conhecimento aos profissionais envolvidos.

O Engenheiro $\mathrm{C}$ comentou sobre o desenvolvimento de trabalho em grupo, quanto aos responsáveis por tarefas específicas, dando como exemplo a manutenção de equipamento novo. Esta atividade para ser desenvolvida necessita que o grupo adquira novos conhecimentos e, posteriormente, venham a dissemina-los aos demais profissionais, inclusive de outras equipes.

Tal realidade guarda correlação com a Capacidade Absortiva Potencial de Assimilação explorada por Zahra e George (2002), quando os autores descrevem que quanto maiores forem a experiência e base de conhecimento prévio, melhor será o direcionamento e a eficiência da capacidade de assimilação do conhecimento obtido externamente. Tal assertiva foi explorada na fala do Engenheiro $\mathrm{C}$ ao discorrer que a capacidade de assimilação da equipe é alta em decorrência do conhecimento prévio que cada um tem na manutenção. Já o Engenheiro B expôs que ao conseguir assimilar o conhecimento para si, consegue repassar aos demais colegas de equipe, enquanto que o $\mathrm{C}$ comentou possuir uma ferramenta de avaliação isonômica oriunda da área de Recursos Humanos da empresa, que o permite avaliar os colaboradores de modo a perceber se determinado conhecimento foi assimilado por um profissional em função do melhor desempenho apresentado posteriormente. Assim, quanto mais capacitação e formação for disponibilizadas aos colaboradores, maior será a capacidade individual para assimilação e utilização de novos conhecimentos na empresa, aumentando a influência positiva no nível de Capacidade Absortiva em prol das manutenções executadas serem mais bem sucedidas.

Os respondentes demonstraram que a Capacidade Absortiva Realizada de Transformação faz parte da área de manutenção na Empresa Inova, uma vez que é justamente a capacidade de desenvolver e refinar as rotinas e práticas que permite combinar novos conhecimentos com a base de conhecimento prévia existente. Isto se dá por meio da adição de conhecimentos, eliminação de conhecimentos defasados ou obsoletos ou ainda pela abordagem de diferentes formas de percepção dos colaboradores acerca dos conhecimentos necessários. A transformação contínua de conhecimentos facilita a identificação de oportunidades de melhorias e resolução de problemas.

Uma questão positiva identificada na pesquisa é que todos os entrevistados concordaram quanto à capacidade de 
aprendizagem de novos conhecimentos por parte dos profissionais da área de manutenção. Isto facilita o acesso ao conhecimento externo e, neste sentido, acaba por auxiliar a empresa a alcançar e implementar inovações na área de manutenção, seja pela modificação de processos ou pela aquisição de novas máquinas e equipamentos e, por conseguinte, melhorar o desempenho e qualidade da área de manutenção.

Na dimensão Capacidade Absortiva Realizada de Explotação, Zahra e George (2002) descrevem que a explotação seja a capacidade de uma organização incorporar o conhecimento adquirido, assimilado e transformado suas operações. Ou seja, esta dinâmica ocorre mediante a capacidade de refinar, desenvolver e/ou trocar as competências existentes por novas, por meio da incorporação de novos conhecimentos nas rotinas operacionais, a exemplo da área de manutenção. No Quadro 5 são apresentados os resultados da pesquisa, segregados a partir da classificação proposta por Zahra e George (2002).

Quadro 5 - Resultados/Evidências encontradas na Capacidade Absortiva a partir da classificação proposta por Zahra e George (2002)

\begin{tabular}{|c|c|c|c|c|}
\hline Categoria & Dimensão & Descrição & Autores & Resultados/Evidências \\
\hline \multirow{4}{*}{$\begin{array}{l}\text { CAPACIDADE } \\
\text { ABSORTIVA }\end{array}$} & $\begin{array}{l}\text { CAPAQ - } \\
\text { Capacidade } \\
\text { Absortiva } \\
\text { Potencial de } \\
\text { Aquisição }\end{array}$ & $\begin{array}{l}\text { Refere-se à capacidade da } \\
\text { organização para identificar } \\
\text { e adquirir conhecimento } \\
\text { gerado externamente e } \\
\text { crítico para sua operação. }\end{array}$ & \multirow{4}{*}{$\begin{array}{c}\text { Zahra e } \\
\text { George } \\
(2002)\end{array}$} & $\begin{array}{l}\text { Na "Empresa Inova" a Capacidade Absortiva Potencial está caracterizada pela ênfase no apoio } \\
\text { interdepartamental para resolver problemas. } \\
\text { Disseminando conceitos e ideias relevantes, pela busca e interesse por informações } \\
\text { pertinentes à área e além da área, em que ao término todos acabam por agregar valor, agregar } \\
\text { conhecimento; } \\
\text { Tem também o trabalho em grupo, responsáveis por tarefas, por exemplo, a manutenção de } \\
\text { um equipamento novo. }\end{array}$ \\
\hline & $\begin{array}{l}\text { CAPAS - } \\
\text { Capacidade } \\
\text { Absortiva } \\
\text { Potencial de } \\
\text { Assimilação }\end{array}$ & $\begin{array}{l}\text { Permitem analisar, } \\
\text { processar, interpretar e } \\
\text { entender a informação de } \\
\text { fontes externas. O fator que } \\
\text { promove a assimilação de } \\
\text { conhecimento é a } \\
\text { compreensão. }\end{array}$ & & $\begin{array}{l}\text { Quanto maiores forem a experiência e base de conhecimento prévio, melhor será o } \\
\text { direcionamento e a eficiência das capacidades de assimilação do conhecimento obtido } \\
\text { externamente; } \\
\text { Fazem avaliação isonômica, que permite que avaliem os colaboradores e percebem se foi } \\
\text { assimilado o conhecimento em função do melhor desempenho apresentado posteriormente; } \\
\text { Quanto mais educação e formação, maior é a capacidade individual para assimilação e } \\
\text { utilização de novos conhecimentos, aumentando a influência positiva no nível de Capacidade } \\
\text { Absortiva e assim as manutenções executadas serem mais bem sucedidas. }\end{array}$ \\
\hline & $\begin{array}{l}\text { CART - } \\
\text { Capacidade } \\
\text { Absortiva } \\
\text { Realizada de } \\
\text { Transformação }\end{array}$ & $\begin{array}{l}\text { É a capacidade de } \\
\text { desenvolver e refinar as } \\
\text { rotinas e práticas que } \\
\text { combinam o novo } \\
\text { conhecimento com a base } \\
\text { de conhecimento prévio. }\end{array}$ & & $\begin{array}{l}\text { Uma questão positiva é que as lideranças concordam quanto à capacidade de aprendizagem } \\
\text { de novos conhecimentos, facilitando o acesso ao conhecimento externo e neste sentido auxilia } \\
\text { a empresa a alcançar a inovação na área de manutenção (com a modificação dos processos } \\
\text { ou aquisição de novas máquinas e equipamentos) e, por conseguinte melhorar o desempenho e } \\
\text { qualidade da área de manutenção; } \\
\text { As redes informais também são importantes na identificação e assimilação de novos } \\
\text { conhecimentos por meio da integração social ao proporcionar a transferência de } \\
\text { conhecimentos tanto tácito como explícito. }\end{array}$ \\
\hline & $\begin{array}{l}\text { CARE - } \\
\text { Capacidade } \\
\text { Absortiva } \\
\text { Realizada de } \\
\text { Explotação }\end{array}$ & $\begin{array}{l}\text { Capacidade de refinar, } \\
\text { desenvolver e/ou trocar as } \\
\text { competências existentes por } \\
\text { novas, através da } \\
\text { incorporação, nas rotinas } \\
\text { operacionais. }\end{array}$ & & $\begin{array}{l}\text { A gestão apoia e disponibiliza essa possibilidade de buscar a proatividade, desenvolver e } \\
\text { trocar as competências existentes por novas através da incorporação nas rotinas do trabalho } \\
\text { da manutenção; } \\
\text { A empresa é capaz de modificar rapidamente seus processos e serviços em função de novos } \\
\text { conhecimentos importantes e impactantes ao desenvolvimento da área e da empresa; } \\
\text { A empresa aplica um conjunto de fatores internos de conhecer, aprender, assimilar, } \\
\text { transformar e implantar como mecanismos de integração social, facilitando o } \\
\text { compartilhamento, a explotação e utilização de conhecimentos. }\end{array}$ \\
\hline
\end{tabular}

Fonte: Autores.

Os entrevistados concordam que a gestão apoia e disponibiliza essa possibilidade de buscar a proatividade, desenvolver e trocar as conhecimentos e competências existentes por novos através da incorporação nas rotinas do trabalho da manutenção. A Empresa Inova é capaz de modificar rapidamente seus processos e serviços em função de novos conhecimentos importantes e impactantes ao desenvolvimento da área de manutenção e da organização. A empresa aplica como mecanismo de integração social continuada, um conjunto de ações internas para estimular nos profissionais identificar, aprender, assimilar, transformar e implantar novos conhecimentos. Este mecanismo de integração social continuada facilita o compartilhamento, 
explotação e utilização de conhecimentos que acabam aumentando a eficiência de capacidade de assimilação e transformação dos profissionais, o que ocorre de forma sistemática formal ou informalmente.

\subsection{Desempenho e qualidade como elementos influenciados pelo conhecimento}

Darroch (2005) estabelece que a mensuração de desempenho na empresa seja constantemente acompanhada. Assim, foi possível observar que a Empresa Inova possui o melhor desempenho frente aos seus concorrentes quanto ao market share (participação de mercado) automotivo relativamente aos últimos 15 anos. E ainda que nos cinco anos anteriores à execução desta pesquisa se manteve com melhor desempenho que seus concorrentes.

Constatou-se também, conforme indicado pelo Gerente Sênior que a Empresa Inova é líder no mercado. O Engenheiro C confirma que, apesar da retração do mercado verificada nos últimos anos, a Empresa Inova continua bem posicionada e que está conseguindo estabelecer diferenciais percebidos pelos clientes em relação ao desempenho e qualidade de seus produtos. Esse diferencial pode ser creditado, em parte, às práticas de gestão do conhecimento desenvolvidas na empresa, que acabam por interferir positivamente nos produtos disponibilizados ao mercado, devido à qualidade do produto em si, qualidade dos equipamentos, qualidade da manutenção e qualidade da mão de obra. No Quadro 6 são apresentados os resultados da pesquisa, segregados a partir da classificação proposta por Darroch (2005) e Parasuraman, Zheitaml e Berry(1985). 
Quadro 6 - Resultados/Evidências encontradas no Desempenho e Qualidade a partir das classificações propostas por Darroch (2005) e Parasuraman, Zheitaml e Berry(1985).

\begin{tabular}{|c|c|c|c|c|}
\hline Categoria & Dimensão & Descrição & Autores & Resultados/Evidências \\
\hline \multirow{7}{*}{$\begin{array}{l}\text { DESEMPENHO e } \\
\text { QUALIDADE }\end{array}$} & $\begin{array}{l}\text { MCD - } \\
\text { Mensuração } \\
\text { Comparativa de } \\
\text { Desempenho }\end{array}$ & $\begin{array}{l}\text { Avalia as características } \\
\text { Rentabilidade, Quota de } \\
\text { mercado e Crescimento. }\end{array}$ & \multirow{2}{*}{$\begin{array}{l}\text { Darroch } \\
\text { (2005) }\end{array}$} & $\begin{array}{l}\text { O market share de } 2018 \text { e dos últimos } 5 \text { anos a "Empresa Inova " apresenta-se como líder de mercado; } \\
\text { Apesar do mercado retraído, a "Empresa Inova" continua muito bem e estão conseguindo um } \\
\text { diferencial obtido pela gestão do conhecimento que acaba por interferir positivamente num produto } \\
\text { competitivo no mercado, devido à qualidade do produto, qualidade dos equipamentos, qualidade da } \\
\text { manutenção, qualidade da mão de obra, fazendo com que a empresa esteja bem no mercado. }\end{array}$ \\
\hline & $\begin{array}{l}\text { MID - } \\
\text { Mensuração } \\
\text { Interna de } \\
\text { Desempenho }\end{array}$ & $\begin{array}{l}\text { Avalia a visão subjetiva do } \\
\text { executivo sobre o próprio } \\
\text { desempenho da organização } \\
\text { e o nível de cumprimento } \\
\text { dos objetivos } \\
\text { organizacionais. }\end{array}$ & & $\begin{array}{l}\text { Metas de desempenho interno são acompanhadas e controladas mensalmente pelo Sistema de } \\
\text { Gestão à Vista, ou seja, as metas são estabelecidas e acompanhadas mês a mês e são apresentadas a } \\
\text { todos; } \\
\text { Nova interpretação da jardinagem da empresa, ocasionando uma redução de custos de três vezes do } \\
\text { que se gastava anteriormente; } \\
\text { Indicadores de manutenção como " MTBF, MTTR" servem para medir o tempo de disponibilidade } \\
\text { de máquina ou equipamento e estão sendo atingidos. }\end{array}$ \\
\hline & $\begin{array}{l}\text { TQ - } \\
\text { Tangibilidade na } \\
\text { Qualidade }\end{array}$ & $\begin{array}{l}\text { Diz respeito às instalações } \\
\text { físicas, equipamento, } \\
\text { pessoal e material que } \\
\text { podem ser percebidos pelos } \\
\text { cinco sentidos humanos. }\end{array}$ & \multirow{5}{*}{\begin{tabular}{|} 
Parasuraman, \\
Zheitaml e \\
Berry (1985)
\end{tabular}} & $\begin{array}{l}\text { Pode-se constatar a qualidade das instalações, obras e serviços de manutenção, o mesmo pode } \\
\text { ser dito com relação aos equipamentos utilizados; } \\
\text { Indústria } 4.0 \text { implantada buscando inovar para garantir a competitividade, entretanto por meio do } \\
\text { conhecimento técnico conseguem fazer a manutenção desta unidade de última geração com } \\
\text { equipamentos de ponta, como das outras unidades que são compostas de instalações antigas; } \\
\text { Verificável no acordo de qualidade com as áreas, como nas pesquisas de satisfação respondidas. }\end{array}$ \\
\hline & $\begin{array}{l}\text { CQ - } \\
\text { Confiabilidade } \\
\text { na Qualidade }\end{array}$ & $\begin{array}{l}\text { Retrata um desempenho } \\
\text { consistente, isento de não } \\
\text { conformidade; deve cumprir } \\
\text { com o que foi prometido, } \\
\text { sem a possibilidade de } \\
\text { retrabalhos. }\end{array}$ & & $\begin{array}{l}\text { A gestão do conhecimento vai nos permitir um nível de zero retrabalho; } \\
\text { Nos serviços planejados a equipe tem competência e confiança muito alta para fazer isso; } \\
\text { A Confiabilidade traduzida na habilidade de executar de forma segura e eficiente o serviço foi } \\
\text { devidamente retratada pelos gestores como sendo um desempenho consistente, isento de não } \\
\text { conformidade, no qual o usuário pode confiar; } \\
\text { Ainda tem retrabalhos em serviços emergenciais e parte dos serviços de terceiros devido } \\
\text { turnover. }\end{array}$ \\
\hline & $\begin{array}{l}\text { RQ - } \\
\text { Responsividade } \\
\text { na Qualidade }\end{array}$ & $\begin{array}{l}\text { Atender voluntariamente aos } \\
\text { usuários, prestando um } \\
\text { serviço de forma atenciosa, } \\
\text { com precisão e rapidez de } \\
\text { resposta. }\end{array}$ & & $\begin{array}{l}\text { A manutenção tem o princípio de atender os clientes o mais rápido possível; } \\
\text { Atividades executadas por terceiros devido turnover pode apresentar dificuldades em novos } \\
\text { integrantes; } \\
\text { Proatividade individual, pois mesmo tendo padrões há o conhecimento tácito de cada um; } \\
\text { Diminuição do grupo de atendimento de manutenção gera um tempo de atendimento maior; } \\
\text { Transmitir os conhecimentos tácitos dos funcionários mais antigos para conhecimentos explícitos } \\
\text { aos demais. }\end{array}$ \\
\hline & $\begin{array}{l}\text { GQ - Garantia } \\
\text { na Qualidade }\end{array}$ & $\begin{array}{l}\text { É identificada como a } \\
\text { cortesia, o conhecimento } \\
\text { dos trabalhadores e sua } \\
\text { habilidade de transmitir } \\
\text { confiança. }\end{array}$ & & $\begin{array}{l}\text { A Garantia identificada como o conhecimento dos trabalhadores e sua habilidade de transmitir } \\
\text { confiança nos serviços executados é constante na área de manutenção ; } \\
\text { O pessoal próprio bem como os terceiros são treinados e têm uma experiência muito grande que } \\
\text { acaba por se refletir nos serviços executados; } \\
\text { Existe o acordo de qualidade com os clientes, que estabelece os desejos, quais serão os indicadores } \\
\text { de avaliação e medição, os métodos de medição, os meios de comunicação e os estágios de escalação, } \\
\text { estabelecendo uma garantia de qualidade e atendimento aos clientes. }\end{array}$ \\
\hline & $\begin{array}{l}\text { EQ - Empatia } \\
\text { na Qualidade }\end{array}$ & $\begin{array}{l}\text { Relata se a organização } \\
\text { importa-se com o usuário e } \\
\text { o assiste de forma } \\
\text { individualizada, capacidade } \\
\text { de demonstrar interesse e } \\
\text { atencão personalizada. }\end{array}$ & & $\begin{array}{l}\text { As visitas feitas pelo Gerente Sênior aos clientes demonstra acessibilidade, sensibilidade e esforço } \\
\text { em entender as necessidades dos usuários; } \\
\text { Fazer o primeiro atendimento por telefone e na sequência ir ao local entender o que precisa ser feito, } \\
\text { se o serviço é emergencial, ou se é possível planejá-lo; } \\
\text { Não ter uma corretiva, não ter uma parada involuntária no meio do processo, não querer enxergar que } \\
\text { tem manutencão trabalhando, preferencialmente ter somente preventivas. }\end{array}$ \\
\hline
\end{tabular}

Fonte: Autores.

Todos os respondentes indicaram que a Mensuração Interna de Desempenho faz parte dos procedimentos da área de manutenção na Empresa Inova. As metas de desempenho interno são acompanhadas e controladas periodicamente. Além do gestor responsável por cada meta, todos os profissionais envolvidos têm como acompanhar o desempenho pelo sistema de gestão implantado, ou seja, as metas são estabelecidas e acompanhadas periodicamente, sendo apresentadas a todos os profissionais da equipe.

A mesma percepção foi expressada pelo Gerente $\mathrm{C}$ ao descrever que indicadores de manutenção tais como o MTBF (Mean Time Between Failures ou Tempo Médio Entre Falhas) e MTTR (Mean Time To Repair ou Tempo Médio Para Reparo) servem para mensurar o tempo de disponibilidade de máquina ou equipamento. Ambos os índices são utilizados como ponto de referência para tomada de decisão de manutenção, pois o objetivo é sempre aumentar o MTBF e diminuir o MTTR. Dependendo dos indicadores em questão, pode-se ainda avaliar uma equipe ou indivíduo específico, sabendo se este está apresentado melhor ou pior desempenho em relação ao histórico de indicadores e às metas estabelecidas.

Baseando-se na resposta do Engenheiro $\mathrm{C}$ de que a área tem atingido todas as metas de forma reiterada, evidencia-se 
que as metas estão sendo alcançadas e, por conseguinte, os indicadores de desempenho da área, o que pode ser comprovado nos quadros de gestão à vista de todos os profissionais da área de manutenção da empresa.

Tais resultados guardam relação com os preceitos indicados por Parasuraman, Zheitaml e Berry (1985) quanto á percepção e avaliação da qualidade dos serviços, notadamente quanto à tangibilidade, confiabilidade, responsividade, garantia e empatia percebidas. Os respondentes comprovaram que estas cinco dimensões da Qualidade fazem parte da área de manutenção na Empresa Inova.

Outro achado relevante da pesquisa de campo executada volta-se ao relato dado Engenheiro B em relação ao fato de o conhecimento técnico ser decisivo para a ações de manutenção desta unidade de última geração com equipamentos de ponta instalados, bem como de outras unidades que são compostas por instalações mais antigas. Assim, tanto os novos como os antigos equipamentos, mediante disseminação do conhecimento dos profissionais de manutenção de modo formal ou informal, conseguem atender aos desejos de seus clientes internos. Essa afirmação foi devidamente constatada tanto no acordo de qualidade firmado internamente com as áreas, como nas pesquisas de satisfação respondidas pelos clientes.

A área de manutenção promove a empatia junto ao cliente, que inclui acessibilidade, sensibilidade e esforço em entender as necessidades dos usuários. Dessa forma, as visitas feitas pelo Gerente Sênior aos clientes demonstram esta acessibilidade, bem como o esforço em compreender e atender as necessidades destes mediante a utilização dos conhecimentos dos profissionais da área de manutenção.

\section{Conclusão}

Esta pesquisa teve como objetivo identificar e descrever como as práticas de gestão do conhecimento e a capacidade absortiva têm sido utilizadas para a melhoria do desempenho e qualidade da área de manutenção de uma indústria automobilística do $\mathrm{ABC}$ paulista.

Pôde-se constatar que na Empresa Inova existe a adoção de práticas de gestão do conhecimento em sua área de manutenção. Parte destas práticas é utilizada como recurso capaz de levar a área de manutenção a um estado de cooperação com outras áreas, uma vez que sua atuação depende de muitos conhecimentos e saberes e diversas competências dos profissionais envolvidos, sendo um grande desafio integrá-los em um único sistema. Ao relacionar o referencial teórico aos dados encontrados nas entrevistas com os gestores da Empresa Inova foi possível afirmar que as proposições permitiram confirmar que as práticas de gestão do conhecimento influenciam na capacidade absortiva da empresa. Constatou-se, ainda, que a capacidade absortiva realizada influencia diretamente no desempenho e qualidade da área de manutenção. Verificou-se também que o desempenho e a qualidade são influenciados pelo conhecimento aplicado pelos profissionais da área de manutenção.

Em razão os achados na pesquisa de campo executada, entende-se que as práticas de gestão do conhecimento são mais relevantes por terem influência direta na capacidade absortiva e no desempenho e qualidade dos serviços de manutenção da empresa. Outro aspecto a observar volta-se ao modelo de Zahra e George (2002), no qual os mecanismos de interação social determinam a eficiência da transformação da capacidade absortiva potencial para a capacidade absortiva realizada. Por consequência, o que ficou evidenciado nesta pesquisa é que as diversas dimensões das práticas de gestão do conhecimento impactaram tanto na capacidade absortiva potencial, quanto na capacidade absortiva realizada.

Esta pesquisa evidenciou, também, que se as organizações derem maior atenção à gestão do conhecimento poderão efetivamente fazer uso de vantagem competitiva sobre seus concorrentes ao canalizarem tais esforços em prol da capacidade absortiva de seus profissionais e equipes. E quanto mais desenvolvida for a capacidade absortiva realizada, maior a probabilidade de criar sustentar vantagens competitivas duradouras. A busca e a necessidade de gerar conhecimentos novos e 
valiosos são inerentes à cultura organizacional estabelecida na Empresa Inova. A cultura organizacional, particularmente o empowerment, atribuído aos funcionários, tem influência sobre o nível de capacidade absortiva das equipes, visto que a base de conhecimento existente aumenta a capacidade de buscar, assimilar, transformar e utilizar novos conhecimentos em prol da empresa. Este processo se perfaz como uma procura intencional e é realizado com fontes de conhecimento internas e externas necessitando, assim, de acompanhamento e apoio contínuos da alta gestão.

Em relação à contribuição prática desta pesquisa, é possível afirmar que quanto mais a organização explora as práticas de gestão de conhecimento numa determinada área, mais rapidamente tenderá a aumentar a Capacidade Absortiva nessa área. Entretanto, vale ressaltar que as empresas possuem diferentes Capacidades Absortivas, justamente porque a capacidade de absorver conhecimento é diferenciada de empresa para empresa. Convém ressaltar que possuir conhecimento valioso numa área é uma condição necessária para a promoção da Capacidade Absortiva Potencial, mas não isoladamente suficiente para gerar mudanças na prática. É necessário desenvolver habilidades para transformar e explotar os conhecimentos para aumentar a Capacidade Absortiva Realizada.

A presente pesquisa apresenta algumas limitações, como a aplicação de estudo de caso único, que não permite generalizações para outras organizações. Também o recorte temporal do fenômeno observado deve ser considerado como um limitador desta pesquisa, uma vez que apresentou os resultados da temática abordada num momento específico do histórico de evolução da organização enfocada.

Como sugestões para trabalhos futuros sobre práticas de gestão do conhecimento e capacidade absortiva recomendase abordar outras áreas e funções organizacionais além da manutenção industrial. Há também a possibilidade de novas pesquisas serem executadas em outros tipos de organizações, que não empresa automobilística, incluindo-se inclusive outras regiões e países. Amparando-se nos resultados ora apresentados neste estudo, novas pesquisas poderiam debruçar-se sobre outros atores/profissionais participantes dos processos analisados, incluindo-se assim não só gestores e profissionais técnicos da empresa sob análise, mas também outros profissionais externos à empresa de forma a comparar a convergência ou divergência nos resultados encontrados nesta pesquisa.

\section{Referências}

Ali, I., Musawir, A. U., \& Ali, M. (2018). Impact of knowledge sharing and absorptive capacity on project performance: The moderating role of social processes. Journal of Knowledge Management, 22(2), 453-477.

Andreeva, T. \& Ikhilchik, I. (2011). Applicability of the SECI Model of Knowledge Creation in Russian Cultural Context: Theoretical analysis. Knowledge and Process Management, 18(1), 56-66.

Balle, A. R. (2019). Relacionamento entre compartilhamento do conhecimento, capacidade absortiva e performance em times ágeis. Tese de doutorado, Universidade de Lisboa, Lisboa, Portugal.

Bernardo Junior, R., Stefanelli, N. O., Oliveira, B. G., Freitas, R. R. \& Freitas, P. de J. (2018). Rethinking the resource based view: a theoretical essay on resources sharing for obtaining competitive advantage. Revista Brasileira de Estratégia. 11(3), 356-367.

Bessi, V. G., Penedo, K. da S., Bez, M. R. \& Dusan, S. (2017). Práticas de gestão do conhecimento em empresas do Vale do Rio dos Sinos /RS. Revista Gestão e Planejamento, 18, 311-329.

Bjorvatn, T., \& Wald, A. (2018). Project complexity and team-level absorptive capacity as drivers of project management performance. International Journal of Project Management, 36(6), 876-888.

Cohen, W. M. \& Levinthal, D. A. (1990) Absorptive capacity: a new perspective on learning and innovation. Administrative Science Quarterly, 35(1), 128152 .

Darroch, J. (2005). Knowledge management, innovation and firm performance. Journal of Knowledge Management, 9(3), 101-115.

Dávila, G. A. (2016). Relações entre práticas de Gestão do conhecimento, capacidade absortiva e desempenho: evidências do sul do Brasil. Tese de doutorado, Universidade Federal de Santa Catarina, Florianópolis, SC, Brasil.

Dávila, O. S. \& Silveira-Martins, E. Proposição/validação de escala para mensuração de capacidade dinâmica produtiva. Revista Eletrônica de Estratégia \& Negócios, 10(1), 285-311. 
Eisenhardt, K.M. \& Santos, F. M. (2000). Knowledge-based View: A new theory of strategy? In A. Pettigrew, H. Thomas \& R. Whittington (Eds.) Handbook of strategy and management. Sage.

Ferreira, G. C., \& Ferreira, J. J. (2017). Absorptive capacity: An analysis in the context of Brazilian family firms. Revista de Administração Mackenzie, 18(1), 174-204.

Godoy, A. S. (1995). Pesquisa qualitativa: tipos fundamentais. Revista de Administração de Empresas, 35(3), $20-29$.

Guedes, H. de P., Ziviani, F., Paiva, R. V. C., Ferreira, M. A. T., \& Herzog, M. M. (2017). Assessment of absorptive capacity: A study in Brazilian manufactures of solar panels. Gestão \& Produção, 24(1), 50-63.

Ichijo, K. \& Nonaka, I. (2007). Knowledge creation and management: new challenges for managers. Oxford University.

Kardec, A. \& Nascif, J. (2001). Manutenção - Função estratégica. QualityMark.

Kang, H. S., Lee, J. Y., Choi, S. S., Kim, H., Park, J. H., SON, J. Y., Kim, B. H. \& Noh, S. D. (2016). Smart manufacturing: Past research, present findings, and future directions. International Journal of Precision Engineering and Manufacturing-green Technology, 3(1), 11-128.

Kaplan, R. S. \& Norton, D. P. (2001). Transforming the balanced scorecard from performance measurement to strategic management (part I). Accounting Horizons, 15(1), 87-104.

Kianto, A. \& Andreeva, T. (2014). Knowledge management practices and results in service-oriented versus product-oriented companies. Knowledge and Process Management, 21(4), 221-230.

Kogut, B. \& Zander, U. (1995). Knowledge and the speed of the transfer and imitation of organizational capabilities: An empirical test. Organization Science, 6(1), European Perspective on Organization Theory, 76-92.

Kotler, P. \& Keller, Kevin L. (2018). Administração de marketing. Prentice Hall.

Kuniyoshi, M. S. (2008). Institucionalização da gestão do conhecimento: um estudo das práticas gerenciais e suas contribuições para o poder de competição das empresas do setor elétrico-eletrônico. Tese de doutorado, Universidade de São Paulo, São Paulo, SP, Brasil.

Kurtz, D. J., Santos, J. L. S. \& Steil, A. V. (2013). Capacidade de absorção do conhecimento e capacidades dinâmicas no contexto de ambientes turbulentos: uma análise da literatura. Anais do IV Encontro da Administração da Informação da ANPAD - EnADI, Bento Gonçalves, RS, Brasil.

Lemos, M. A., Albernaz, C. M. R. M. \& Carvalho, R. A. (2011). Qualidade na manutenção. Anais do XXXI Encontro Nacional de Engenharia de Produção. Belo Horizonte, MG, Brasil.

Moraes, A. T de. (2019). Sistematização dos microprocessos da capacidade absortiva para identificação do conhecimento em gestão de projetos. Dissertação de mestrado, Universidade Nove de Julho, São Paulo, SP, Brasil.

Morais, M. de O., Costa Neto, P. L. de O., Santos, O. S., Conceição, M. M., Messias, J. F., Morais, G. A. \& Brejão, A. S. (2020). O conhecimento aliado a inovação, elementos para a melhoria de processos produtivos: estudo de caso em uma fundição de alumínio sob pressão. Research, Society and Development, 9(9), p. e172997419, 2020.Recuperado em https://rsdjournal.org/index.php/rsd/article/view/7419. 10.33448/rsd-v9i9.7419.

Parasuraman, A., Zeithaml, V. A. \& Berry, L. L. (1985). A conceptual modelo of service quality and its implications for future reserch. Journal of Marketing. $49(4), 41-50$.

Pena, M. M., Silva, E. M. S., Tronchin, D. M. R. \& Melleiro, M. M. (2013). O emprego do modelo de qualidade de Parasuraman, Zeithaml, Berry em serviços de saúde. Revista de Enfermagem da USP, 47(5), 1235-1240.

Pereira, A. D. S. \& Macieira, R. A. (2019). A gestão do conhecimento como mecanismo de desenvolvimento de capacidades dinâmicas nas organizações. Revista Pensamento \& Realidade, 34(3), 92-106.

Pereira A. S., Shitsuka, D. M., Parreira, F. J. \& Shitsuka, R. (2018). Metodologia da pesquisa científica. UFSM. https://repositorio.ufsm.br/bitstream/han dle/1/15824/Lic_Computacao_Metodologia-Pesquisa-Cientifica.pdf?sequence=1

Picoli, F. R. \& Takahashi, A. (2016). Capacidade de absorção, aprendizagem organizacional e mecanismos de integração social. RAC - Revista de Administração Contemporânea, 20(1), 1-20.

Pieretti, R. F., Silva, M. M., Lesme, D. A. S. \& Almeida, M. V. de. (2020). Análise de indicadores de desempenho individual aplicado a manutenção industrial. Research, Society and Development, 9(6), p. e129963660. https://rsdjournal.org/index.php/rsd/article/view/3660. DOI: 10.33448/rsd-v9i6.3660.

Popadiuk, S., \& Nunes, S. G. C. (2018). Capacidade de absorção, exploração e explotação: uma análise em empresas de Palmas, Tocantins. Gestão \& Produção, 25(4), 737-750.

Rocha, C. C. da. (2018). A capacidade absortiva como uma capacidade dinâmica. International Journal of Business Marketing, 3(2), 76-87.

Rosa, C., Silva, P. R., Sausen, J. O., Baggio, D. K., Brizolla, M. M. B., Zanatta, J. M. \& Nuske, M. A. (2020). Mudança e adaptação estratégica no contexto do desenvolvimento das capacidades dinâmicas. Research, Society and Development, 9(7), e04973715. https://rsdjournal.org/index.php/rsd/article/view/3715. DOI: $10.33448 / \mathrm{rsd}-\mathrm{v} 9 \mathrm{i} 7.3715$.

Staidel, G. P. \& Romano, C. A. (2020). Avaliação da gestão das empresas construtoras de pequeno e médio porte de Curitiba quanto ao nível de aderência às práticas de gestão do conhecimento. Perspectivas em Gestão \& Conhecimento, 10(3), 47-74.

Teece, D. J., Pisano, G. 7 Shuen, A. (1997). Dynamic capabilities and strategic management. Strategic Management Journal, 18(7), 509-533. 
Research, Society and Development, v. 10, n. 2, e47410212713, 2021

(CC BY 4.0) | ISSN 2525-3409 | DOI: http://dx.doi.org/10.33448/rsd-v10i2.12713

Tubino, D. F. (2017). Planejamento e controle da produção. Atlas.

Vieira, R. C. (2017). Manufatura avançada: a influência da estratégia da manufatura e da percepção de affordances. Dissertação de mestrado. Universidade de São Paulo, São Paulo, SP, Brasil.

Xenos, H. G. (2004). Gerenciando a manutenção produtiva. EDG.

Yin, R. K. (2010). Estudo de caso - Planejamento e métodos. Bookman.

Zahra, S. A. \& George, G. (2002). Absorptive capacity: A review, reconceptualization, and extension. Academy of Management Review, 27(2), 185-203. 